Paper presented at the Cryogenic Engineering Conference and International Cryogenic Materials Conference, August 12-16, 1985, Massachusetts Institute of Technology, Cambridge, MA.

CONF-850814---10

DE85 018444

\title{
THREE COMPUTER CODES FOR SAFETY AND STABILITY \\ OF LARGE SUPERCONDUCTING MAGNETS*
}

\author{
Larry R. Turner \\ Fusion Power Program \\ Argonne National Laboratory \\ Argonne, IL 60439
}

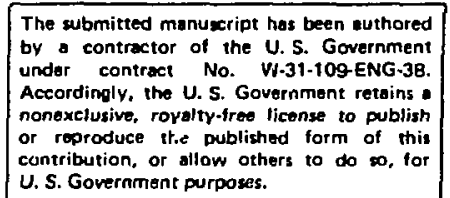

DISCLAIMER

\begin{abstract}
This report was prepared as an account of work sponsored by an agency of the United States Government. Neithe: the United States Government nor any agency thereof, nor any of their employees, makes any warranty, express or implied, or assumes any legal liability or responsibility for the accuracy, completeness, or usefulness of any information, apparatus, product, or process disclosed, or represents that its use would not infringe privately owned rights. Reference herein to any specific commercial product, process, or service by trade name, trademark, manufacturer, or otherwise does not necessarily constitute or imply its endorsement, recommendation, or favoring by the United States Government or any agency thereof. The views and opinions of authors expressed herein do not necessarily state or reflect those of the United States Government or any agency thereof.
\end{abstract}

\footnotetext{
* This work supported by the U.S. Department of Energy.
} 
THREE COMPUTER CODES FOR SAPETY AND STABILITY OF LARGE

\title{
SUPERCONDUCTING MAGNETS*
}

\author{
Larry R. Turner \\ Fus1on Power Program \\ Argonne National Laboratory \\ Argonne, I111no1s
}

\begin{abstract}
For analyzing the safety and stability of large superconducting magnets, three coaputer codes TASS, SHORTURN, and SSICC have been developed, applicable to bath-cooled magnets, bath-cooled magnets with shorted turns, and agnets with internally cooled conductozs respectively. The TASS code la described, and the use of the three codes 18 reviewed.
\end{abstract}

\section{INTRODUCTION}

A large siperconducting magnet must be both stable and safe thermally. Stability anslysis determines what happens when a section $o_{i}$ conductor becomes normal conducélng due to a mechantcal perturbation or other heat input. To be cryostable, the magnet must have adequate cooling to return the conductor to the superconducting state. To be safe, on the other hand, the magnet must respond to any credible abnormal conditions in a way that w1l not endanger the public, the operators, ther systems, or the magnet itself.

Three safety and stability coroputer codes which have been developed at Argonne National Laboratory (ANL) w1ll be described here: TASS (Therwal Analysis for Safety and Stablitty), used to snalyze the stability of a pool bolling cryostab): magnet or its safety under different off-norasi conditions; SHORTURN, used to analyze the safety of a cryostable magnet with shorted turn or turns; and SSICC (Safety and Stability of Internally Cooled Conductors), used to analyze magnets with internally cooled conductors (ICC). The codes had their origins in the need to anslyze superconducting magnets belng bullt for MHD research and have been developed as part of the progran to ensure the safety of fusion reactors.

\section{TASS}

The program iasS originated as a stabllity sode.' It proved useful in atudying the stablity of the MHD wagnet buflt at Argonne National Lab-

* Work supported by EGSG Idaho, Inc. and the U.S. Department of Energy, Idaho Operatione office, under Contract No. DE-AC07-76 IDO 1570. 
oratory for the Cosi-fired Plow Pacllity at the University of Tennessee Space Institute. 2 It was modifled, priwarlly by changing frow the forward difference wethod to the backward difference method, for atudying the safety of that agnet. ${ }^{3}$ Finally it was generallzed for use in studying the quench properties of fusion magnets, as part of the fusion safety prograw. ${ }^{4}$ It has been successfully used it the Fusion Engineering Design Center, Oak RIdge National Laboratory, ${ }^{5}$ and has been diotributed elsewhere in the fusion magnet community.

Since its initial distribution, the code has been modified falrly extensively to broaden $1: 8$ applicability and to incorporate new data on physical properties, especially critical current density and transient heat trangfer.

\section{Applications of TASS}

Stability. In stal lity anslysis, a current and perturbing heat pulse are speci三led for a conductor otherwise operating under design conditions. Consideration of only a short time (a second or so) and a short length (a meter or so) will determine whether the noras region will collapse, grow without limit, or reach a steady state.

Uncovered conductor. An all too credible abnormal condition for a bath-cooled magnet 18 a low liquid level, resulting in a length of uncovered conductor. In TASS, such a length can be specifled, elther uncooled or vapor cooled by free convection. The heat transfer for convective vapor cooling is calculated from the Rayleigh number, using the temperature dependent properties of 1 atm hellum vapor.

Hellum depletion and replenishment in cooling channels. A nominally cryostable bath-cooled wagnet may not be stable agalnst large heat pulses. The pulse, and subsequent joule heating, may vaporize all the hellum around the conductor. Replenishment of the liquid may then be too 810 to return the conductor to its superconducting atate.

The computer code TASS has now been modiried so that during a time step $\Delta t$ the fraction $f$ of the channel volume of an element which is filled with liquid 1s changed by" an amount $\Delta f$,

$$
\Delta f=r \Delta t-\Delta q / q_{l}
$$

where: $q, 18$ the heat needed to f1ll the channel with vapor, $\Delta q 18$ the heat which the element transfers to the hellum in the cooling channel, and $r$ is the reclprocal of the time needed to replenish the liquid in a vapor fllled channel. The fraction $f$ is constralned to lle between zero and one. The available experimental data ${ }^{6}$ on depletion and replenishment 18 Inadequate to estimate the constant $r$ or to teat Eq. (1).

Changing current. Under off-normal conditions, the current may vary. The abnoral condition may consist of a specifled varying current, or the augnet may be discharged in response to the abnormal conditions. Either of these can be treated in TASS.

For a discharging magnet, the power dissipated internally in norma: regions of conductor and externally in the discharge resistor 18 calculated each step. The stored energy, Inttialized Erow the current and Inductance, 1a decreased each step, and the new value of current calculated. The magnetic field value, used in calculating critical current each step, can be decreased proportionally with the current. 
Space variation of angetic fleld. A characteriatic property of tokanak TF (toroldal field) colle, and sone other cryostable magnets as well, is the variation of the angaetic fleld B around a turn of the coll. The fleld can vary by nore than a factor of two over a distance of a few wetera, a can field dependent parameters euch as critical current, resiativity, and propagation velocity. This situation peraits the poselbility of able normal region of conductor, which never propagates into the low fleld region nor collapsea in the high field region. TASS has demonetrcted thls effect.

Operation with HeIL. Stabllity analysis of conductors cooled by superfluid hellure has been Incorporated Into TASS, using the approach of Meuris, et al. 7 As it has not been thoroughly tested, it will not be described here.

\section{Operation of TASS}

Heat balince. In the program, the conductor befng nodeled 18 discretized Into elewents long 1 ts length. A heat balance is applied to each element to compute the teaperature of each elenent at each time $B$ tep. From the temperature diatribution, the program tracks the development of any normal region of conductor.

The heat flow into the elenent arises frow nuclear radlation, frictional notion, or external heating. These are represented by an applied heat flux $Q_{a p p}$. If the element ia in the normal or current sharing state, heat wll also be produced by resistive joule heating $Q_{\mathrm{J}}$ •

Heat may flow out of the element through heat transfer to the hellum coolant $Q_{H e}$, and through conduction to neighboring conductor elements

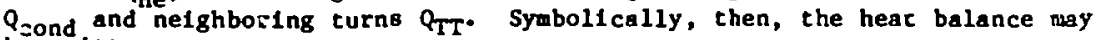
be written as:

$$
Q_{\text {app }}+Q_{J}=Q_{H e}+Q_{\text {cond }}+Q_{T T}+Q_{\text {enth }} \text {. }
$$

where $Q_{\text {enth }}$ represents the Increase in enthalpy of the element.

$$
Q_{\text {app }}-\mathbf{P}_{\text {app }} \Delta \ell \Delta t
$$

where $P_{\text {app }}$ is the externally applied heating per unit length of conductor, and $\Delta l$ IfP the element length.

$$
Q_{J}=o_{e} \Delta \ell(1+1 / r) I_{e f f}^{2} \Delta t / A \text {, }
$$

where $p$ is the electrical resistivity of the copper, $r$ is the volume rat to of copper to euperconductor, $A$ - hw $1 \mathrm{~s}$ the cross sectional area of the conductor, and

$$
\begin{aligned}
& I_{\text {eff }}^{2}-I^{2} \quad \text { If the element is fully normal } \\
& -I\left(I-I_{s}\right) \text { If the element } I_{s} \text { above } I_{s} \text {, the critical current } \\
& -0 \quad \text { If the element is fully superconducting } \\
& \quad Q_{H e}-f P_{w} \Delta l q_{h} \Delta t=f P_{w} \Delta l\left(a+B T_{I}\right) \Delta t
\end{aligned}
$$

where $p_{w}$ is the wetted perimeter, and $q_{h}=a+B T_{1} 18$ the heat transfer coefficient ( $\alpha$ and $B$ may themselves be reak functions of $T_{1}$, the temperature of element 1 ). The fraction of cooling avallable, $f, 1 s$ found by Eq. (1). 


$$
Q_{\text {cond }}=\operatorname{st}\left[k_{1,1+1}\left(T_{1}-T_{1+1}\right)+k_{1,1-1}\left(T_{1}-T_{1-1}\right] / \Delta l\right. \text {. }
$$

where $k_{1}+ \pm 1-2\left(1 / k_{1}+1 / k_{1 \pm 1}\right)^{-1}$ is the effective thermal conductivity between elfements 1 and $1 \pm 1 \pm 1$ Use of an averaged thermal conductivity ouch as this is needed so that the heat conducted frow element 1 to $1+1$ is the negative of that conducted from $1+1$ to 1 , as required for overall heat balance.

$$
Q_{T T}=\operatorname{gh\Delta l\Delta t}\left(2 T_{1}-T_{1}^{+}-T_{1}^{-}\right) \text {. }
$$

where $T_{1}^{+}$and $T_{1}^{-}$are the temperatures of the $1-t h$ elements of the two neighboring turns, and $g$ is the effective turn-to-turn conductivity.

$$
Q_{\text {enth }}=V_{\rho_{m}} c_{p}\left(T_{1}-T_{1}^{r}\right) \text {. }
$$

where $V$ is the element volume $(A \Delta L), P_{18}$ the mass density of the conductor, $C_{p} 18$ its epecific heat, and $T_{1}$ is the temperature of element 1 at the previous tine otep.

These e1x equations are substituted into the heat balance equation for each element, which is then divided by $p C y$ to give $1 t$ the units of cemperature. The terms of the equation are Tebrranged to give

$$
\begin{aligned}
& T_{1}\left[1+\left(k_{1,1+1}+k_{1,1-1}\right) \Delta t / p_{m} C_{p}(\Delta L)^{2}+f p_{w} \Delta t \beta / A p_{m} C_{p}+2 g \Delta t / \omega p_{m} C_{p}\right] \\
& -T_{1+1}\left[k_{1,1+1} \Delta t / \rho_{w} r_{p}(\Delta l)^{2}\right]-T_{1-1}\left[k_{1,1-1} \Delta t / \rho_{w} c_{p}(\Delta l)^{2}\right] \\
& =T_{1}-f p_{v i} x \Delta t / A \rho_{m} C_{p}+\rho_{e} I_{e f f}^{2} \Delta t / A^{2} \rho_{m} C_{p} \\
& +P_{a p p} \mathcal{A C / A p _ { m } C _ { p }}+g\left(T_{1}^{+}+T_{1}^{-}\right) \Delta t / w p_{p} C_{p} \text {. }
\end{aligned}
$$

The equations thus obtained for esch element form a tri-diagonal syster of simultaneous equitions which can be solved for $T_{1}$. (Since $Q_{T T} 18$ typlcally vep small compared to $Q_{\text {He }}$ and $Q_{\text {cond, the previously computed }}$ values for $T_{1}$ and $T_{1}^{-}$are used on the right hand side in order to preserve the tri-diagonal fotw. The backward dif Eerence wethod ${ }^{8}$ does not introduce numerical inatability for any ize time increment. The program thus deteralnea the temperature of each element at each time step.

Detal ls of Properties

Transient heat transfer. The translent heat transfer data of Steward and of Giarrantano and Frederick 10 can be represented in a simple form. The expression for nucleate bolling is used:

$$
\mathrm{q}_{\mathrm{h}}=0.8 \Delta \mathrm{T}, \Delta \mathrm{T}<\Delta \mathrm{T}_{\max }
$$

where $q_{h}$ is the heat tranafer in $W / \mathrm{cm}^{2}$ and $\Delta T$ is the remperature difference in kelvin between the conductor ourface and the bulk hellum. For steady state transfer this conditjon is taken to hold for $\Delta \mathrm{T}_{\max }=1 \mathrm{~K}$. Por tranalent transfer, it to taken to hold up to

$$
\Delta T_{\max }=-0.7806 \ln \left(t-t_{0}\right)-2.617
$$

where $t$ is the time and $t_{0}$ the tiae st which $\Delta T$ for the element first exceede $0.1 \mathrm{~K}, t$ and $t_{0}$ ln seconda. For $\Delta T>\Delta T$ max, the expressions are
used for fila bolling or the transition reglon

$$
q_{h}=0.1271+0.0015 \Delta T, \Delta T>2
$$




$$
q_{h}=1.45-0.65 \Delta T, \Delta T_{\max }<\Delta T<2 .
$$

Critical current denalty of NbT1. Because of new data on the critical crirrent density $J_{c}$ of NbT1, particularly at low temperature $T$ and high fleld $B$, we have refit the data over the range $1.8 \mathrm{~K}<\mathrm{T}<8 \mathrm{~K}$, $2 \mathrm{I}<8<14 \mathrm{~T}$. The new expression is

$$
J_{c}=\left(T_{C}-T\right)\left(8.8-0.46 \mathrm{~B}+0.32 / \mathrm{T}-1.31 / \mathrm{T}^{2}\right) \times 10^{5} .
$$

The critical temperature $T_{c}$ 1s taken to be

$$
T_{c}=8.56(1-B / 14.7)^{1 / 2} \text {, }
$$

and $T$ is expresaed in kelvin, B in tes la, and $J_{C}$ in $A / \mathrm{cm}^{2}$.

Number of elenents. For a single turn, thermsily insulated from nelghboring turns, up to 400 elements have been used to model half the conductor. When heat transfer to nelghboring turns is included, up to ninety elenerits have been used in the specifled conductor and in each of the elx turne on either side.

Appropriate element length. Experimental studies of the cryostability of euperconducting wagnets have sometives observed the occurrence of a sable nomal region of conductor (SNR) which netther shrinks out of existence nor propagates to quench the magnet. 11 However, the TASS code way soaetines predict the occurrence of a SNR unrealletically because of too large conductor element length $\Delta l$ being used in the analysis. When the computation is repeated with the use of a smaller element, no SNR is predlicted.

It 1s found that the code w11l predict a SNR when one element, at or near the temperature of maxtmum heat transfur to the coolant 1s just able to transfer to the hellua all of the heat recelved from a nelghboring element. An the heat transferred to he hellum is proportional to $\Delta l$ while the heat recelved through conduction is inversely proportional to $\Delta l$, It follows that a false SNR 1s possible for $\Delta l$ greater than sone critical value. To find the critical value, $Q_{\mathrm{Ke}}$ and $Q_{\text {cond }} f$ rom Eq. (3) and (4) are equated, giving, after rearrangement:

$$
\Delta R \leq \frac{A}{P_{w}} \frac{k\left(T_{m}\right)\left(T_{c}-T_{m}\right)}{T_{h}\left(T_{m}\right)},
$$

where $T_{c}$ 1s the superconductor critical temperature and $T_{m} 18$ the temperature of waximum heat transfer to the hellum. For pool bolling hellum I at $4.2 \mathrm{~K}, \mathrm{~T}_{\mathrm{a}}=5.2 \mathrm{~K}$.

Typ1cal appropriate values for $\Delta l$ are in the range of $0.5-1.0 \mathrm{~cm}$. In any case where TASS predicts a SNR, tt 18 advisable to repeat the analysis using a saller $a l$, perhaps half the original.

Provision is ade to pernit the size of each element to increase as the computation proceeds. When a specifled element of conductor goes normal, three elements can be combined into one. The heat transfer to the heliua by the new element 18 the sum of the heat transferred by the three old ones; the temperature of the new element is the temperature of the widdle one; and the length and electrical resistance of the new element and three timen those of the old ones. 
If turn-to-turn heat conduction is Included, then when an element of a specified turn (e.g., the seventh nesrest neighbor to the Initial turn) goes normal, three turns are thereafter treatcd as one. The heat transferred to the hellun from the new tum is the oum of the heat fron the three old ones; the temperature of the new turn 18 that of the viddle one; the electrical resiatance and turn-to-turn heat conductance are decreased by actor of three; and the width and equivalent current are tripled.

In l1ght of the possibility described above of predicting a false SNR, thls option of 1ncreasing the elenent size mut be used with great caution.

Use of TASS

US-SCMS magnet. TASS was first used to predict the stability of the US-SCMS magnet for MHD research. 12 Consideration of turn to turn conductlon raised the predicted recovery current frow 640 A (classical $q_{h}-0.34$ $\left.W / \mathrm{cm}^{2}\right)$ to $874 \mathrm{~A}\left(\mathrm{class} 1 \mathrm{cal} \mathrm{q}_{\mathrm{h}}=0.64 \mathrm{~W} / \mathrm{cm}^{2}\right)$.

UTSI-CFFF manet. TASS was used to evaluate the stabllity 1,13 of several conductor concepts for the UTSI-CFFP magnet for MHD research. 2 The safety of the magnet with 6 m half turn uncovered and cooled only by vapor was also studied. 3,13

HRS magnet. The former Twelve-Foot Bubble Chamber magnet at ANL has been reconfigured, with horizontal axis, as the High Resolution Spectrometer (HRS) magnet at SLAC. As the f1rst of the large. cryostable magnets, It had a very conservative design, with a copper to superconductor ratio of 80. It 1s end-cooled, and operates at $2000 \mathrm{~A}$ and $1.6 \mathrm{~T}$.

The aggnet was analyzed for the effects of low liquid level, with $3 \mathrm{~m}$ of conductor outalde the llquid. ${ }^{14}$ The analyais showed that the HRS magnet to be safe even in the worst case (no coollng, tree wheeling).

US INTOR 6olenold. The US INTOR design chose a $50 \mathrm{kA}$ cabled conductor developed at Los Alamos National Laboratory (LANL) 15 as the reference conductor of the ohric heating (OH) solenold. Analysis with TASS 5,14 predicted recovery at $50 \mathrm{kA}$ from $2 \mathrm{~cm}$ of conductor initially at $50 \mathrm{~K}(150 \mathrm{~J})$ or $16 \mathrm{ca}$ of conductor $1 \mathrm{nit}$ lally et $50 \mathrm{~K}(1200 \mathrm{~J})$.

Overcurrent in tokamak TF coll. If one toroldal fleld (TF) coll of a tokanak discharges rapidly while the others remaln superconducting and are owtched Into a mode of free-wheeling Individually, the currents can rise in the two neighboring collo and their high fleld regions can become resiative.

In a TASS Imulation," over a wide range of currents, a stable normal region developed, neither growing to the low fteld (3T) leg nor collapsing to the high fleld (9T) leg.

\section{SHORTURN: ANALYSIS OP SHORTED TURNS}

An analysis code SHORTURN has been developed by modifying TASS. In an analysis with SHORTUR, the conductor first goes to the normal state in the nelgborhood of the short; then the normal region propagates along the shorted turn. A study 16 comparing a short analysis of a large MHD dipole vi. SHORTURN with two other methods which assumed a uniform temperature distribution around the shorted turn found a higher temperature with SHORTUKN. 
Analysia of two magnets 17,18 which reportedly had shorted turne has been reported previously,19,20 Under resconable sscueptions of short reslatance and discharge tioes, the General Dynanics and General electric colla of the Large Coll Project 27 were predicted to recover without reaching a high temerature. Simulation of the shorted superconducting coll of the $25 \mathrm{~T}$ to $30 \mathrm{~T}$ hybrid asgnet ayeted ${ }^{10}$ at MIT predicted the sort of periodic voltage splkea observed experimentally. More recently SHORTURH has been sodifled to treat a wagnet with a shorted turn o- turns neighboring a discharging agnet.

\section{INTERNALLY COOLED CONDUCTORS: SSICC CODE}

Condition for the stability of internally cooled conductors are found to depend upon both ateady-state and transient hellum flow. In fact, ICC are found to be highly atable agalnst ghort heat pulses even when the steady tate hellue flow is near zero. 21.22 This effect is attributed to the loproved heat transfer caused by the transient flow of hellum following local heating and pressure rise.

Vincent Arp developed a conputer code 23 for the stability of ICC. His code Incorporates one-dimensionsl energy, mass, and momentum balance within the helium snd predicts the high velocity, high pressure hellum flows, which are not predicted by simpler models.

Arp's code has been wodified and combined with TASS to form the code SSICC (Safety and Stablitty of Internally Cooled Conductor). The SSICC code successfully predicted ${ }^{24}$ the mulciple siabllity reglone observed in the experiments of Lue, Miller, and Dresner.25,26 It was also applied 27 In a thermal safety and stability analysis of the TF colls of the PED (Fusion Energy Device) wagnets 28 which employed ICC.

\section{REFERENCES}

1. L. R. Tinner, S. T. Wang, and J. Harrang, Recovery of a cryostable magnet following aechantcal perturbation: One-dimensional and two-dimensional calculations, IEEE Trans. On Magn., Vol. MAG$15: 371-374$ (1979).

2. S.-T. Wang, et al., The final decign of a superconducting MHD magnet for the coal-fired flow factlity at the University of Tennessee Space Institute, In: "Advances in Cryogenic Engineering", Vol. 25, Plenum Press, New York (1980) pp. 19-29.

3. L. R. Turner, et al., Safety analysis of the UTSI-CFFF superconducting magnet, 1btd, PP. 39-48.

4. L. R. Turner, Safety of superconducting magnetg for fusion: Thermal analyols of large cryostable magnets. IEEE Trans. on Magn., Vol. MAG-17:463-466 (1981).

5. H. M. Stacey, Jr., et al., "US Contribution to the International Tokanak Keactor Phase-1 Workshop," USA INTOR/81-1, Georgla Inst1tuie of Technology, p. V 56 (1981).

6. C.-J. Chen, "Bffects of Transient Heat Transfer and Vapor Forwation on Cryostable Superconductore." Doctoral Dissertation, Dept. of Inforation Engtneering, University of Ililnols at Chicago Circle (3.981).

7. C. Meurls, et al., Stability of superconductors cooled by superfluid heliun at atmoepheric preseure, In: "Stability of Superconductors," Institut International du Frold, Par1s, No. 1981-6, (1981), pp. 215-224.

8. F. S. Action, "Nuwerical Hethode That Work," Harper and Row, New York (1970) pp. 442-445.

9. W. G. Steward, Translent hellum heat transfer: Phase I-shatic coolant, Int1. J. Heat and Mase Trangfer, $21: 863$ (1978). 
10. P. J. Giazrantano and N. V. Prederick, Transient pool bolling of Ilquid hellum using a temperature controlled heater ourface, in: "Advances in Cryogenic Englneering." Vol. 25, Plenum Press, New York (1980) Pp. 455-466.

11. C. Meuris, Influence of an uncooled region on the atablitty of superconducting conductors, 1n: "Stablity of Superconductors," Inotitut Interational du Prold, Parle, No. 1981-6, (1981), pp. 161-168.

12. R. Nelaan, et a1., Superconducting agnet systen U-25 MatD facility, LEEE Trane, on Magn., MG-13:632-635 (1977).

13. L. R. Turner, Superconducting magnet stability and efety analysis, "1980 Superconducting MHD Magnet Design Conf.," MIT (1980) pp. 8286.

14. L. R. Turner, Computation of cryostabllity under normal and abnormal conditions, in: "Stability of Superconductors," Institut International du Prold, Par1s, No. 1981-6, (1981), Pp. 169-174.

15. M. S. Walker, et al., Superconducting design and 1088 analyels for a $20 \mathrm{MJ}$ Induction heating co1l, IEEE Trans. on Magn., MAG-17:908-911 (1981).

16. L. R. Turner and M. A. Hilal, Safety consequences of shorted turns in - cryostable superconducting magnet, IEEE Trans. on Magn. MAG17:2015-2018 (1981).

17. P. L. Walatrom, Short circult detection in the winding and operation of superconducting magnets, IEEE Trans. on Magn. MAG-19:1094-1096 (1983).

18. Y. Iwasa, et al., Diagnosis and analya1s of an electrical short in a superconducting magnet, IEEE Trans. on Magn. MAG-19:704-708 (1983).

19. L. R. Turner, Safety Implications of shorted turns in superconducting aggnets for fusion, 1n: "9th Symposium on Engineering Problemg of Pusion Research," Chicago (1981) pp. 301-304.

20. L. R. Turner, Consequences of shorted turns in superconducting magnet, 1n: "Advances in Cryogenic Engineer1ng," Vol. 29, Plenum Pres8, New York (1984), pp. 255-264.

21. Y. Iwasa, M. O. Hoenig, and D. B. Montgomery, Cryos:ab1lity of a sma.l1 superconducting coll wound with cabled hollow conductor, IEEE Trans. Magn. MiG-13:678-681 (1977).

22. J. H. Lue, J. R. Miller, and L. Dresner, Vapor Locking as a lioftation to the stablity of composite conductors cooled by bolling hellum, In: "Advancea In Cryogenic Engineering," Volume 23, Plenum Press, New York (1978) pp. 226-234.

23. V. D. Arp, Stability and thermal quenches in force-cosled superconducting cables, in: "1980 Superconducting MHD Magnet Design Conf.", MIT, (1980) Pp. 142-157.

24. Lo R. Turner and J. Shindler, Computer simulation of multiple stabil1ty regions in an internaliy cooled superconducting conductor. IEEE Trans, on Magn. MAG-21:1083-1086 (1985).

25. J. W. Lue and J. R. Miller, Heated length dependence of the otability of en Internally cooled superconductor, In: "oth Symposiuin on Engineering Problew of Fusion Research," Chlcago (1981) pp. 652659 .

26. J. W. Iue, J. R. Mller, and L. Dresner, Stablitty of cable-in-conduit superconductora, J. Appl. Phys 51(1):772-783 (1979).

27. L. Turner and $R$. Ryne, Safety and stablity of superconducting magnets for fualon uaing internally cooled conductora, IEEE Trans. on Magn. MAG-19:685-687 (1983).

28. C. A. Planagan, D. Stelner, and G. E. Sufth, "Fusion Englneering Devico Design Description," Oak Ridge National Laboratory, ORNL/TM7948 (1981). 